\title{
Does too much love hinder innovation? Family involvement and firms' innovativeness in family-owned Small Medium Enterprises (SMEs)
}

\author{
Filippo Ferrari $\mathrm{a}^{\mathrm{*}}$ \\ ${ }^{\mathrm{a}}$ School of Economics, Management and Statistics. University of Bologna (Italy)
}

JEL

CLASSIFICATION

0310

KEYWORDS

Family Business; Innovation

propensity;

Circumplex Model;

Family Cohesion;

Family flexibility

\section{CÓDIGOS JEL}

0310

PALABRAS CLAVE Empresa Familiar; propensión a la Innovación;

Modelo

Circumplejo;

Cohesión familiar;

Flexibilidad familiar

\begin{abstract}
Current literature suggests that family involvement has an impact on firms' innovation propensity, but it does not yet seem able to explain in which conditions. Adopting a curvilinear model, (Olson's circumplex model of family) this research demonstrates that the family's cohesion and flexibility levels play a significant role in the relationship between family involvement and firm innovation propensity.

Moreover, by investigating a sample of SMEs $(\mathrm{N}=125)$ quantitatively, this paper also highlights that a curvilinear model shows a better fit (in comparison to linear models) for explaining the family involvement impact on innovation propensity. Finally, implications for both scholars and practitioners are discussed.
\end{abstract}




\section{Introduction}

Family firms have always shown an ambivalent relationship with innovation dynamics. Some scholars found a negative relationship between family business and innovation propensity (Block, 2012; Chen, Hsu, 2009; Chrisman, Patel, 2012); others conversely found a positive relationship (Gudmundson et al., 2003; Kim et al., 2008; Llach, Nordqvist, 2010). Therefore, literature is still inconclusive and seldom suggests an explanation of the relationship between family involvement and innovation levels. On one side, both long-term orientation (Munoz-Bullon et al., 2011; Dieguez-Soto et al., 2016) and social capital could foster the development of new products and processes (Llach, Nordqvist, 2010; Chen, Hsu, 2009; De Massis et al., 2015). On the other side, risk aversion (Chen, Hsu, 2009) and reluctance to make 'horizontal' partnerships (Dohennels, Froling, 1999) could negatively impact the overall innovation rate.

Occasionally literature is even contradictory: for instance, non-family members' exclusion from strategic decisions seems to lead to both negative (Zahara, 2005) and positive (Madanoglu et al., 2016) outcomes in innovation rate. Finally, as suggested by Sciascia et al., (2013), innovation propensity seems to change over time (Zelleweger, Sieger, 2012), but literature lacks of an explanation of this specific feature.

In general, current literature calls for new insights into to what extent, and how, the internal environment of the family affects the governance of the family firm and the family's pursuit of economic and non-economic goals (Arzubiaga et al., 2019; Daspit et al., 2017; Madanoglu et al., 2016). Although some authors (De Massis et al., 2013; Sirmon \& Hitt, 2003) highlight the influence of family involvement on firm's innovation rate, such influence is one of the less understood determinants in the innovation propensity of family firms (Duran et al., 2016). Recently, De Massis and colleagues (2015) affirm that the conditions in which the family has an impact on innovation are still unclear, and research has until now led to inconclusive findings (Craig, Moores, 2006; Morck et al., 2000). Some authors (see for instance Carnes, Ireland, 2013) underline the heterogeneity of families; in that different family firms have different innovative outcomes, but they have been (until now) unable to explain. An as of yet unanswered question is "if familiness [i.e. the outcome of family-firm overlapping] helps both stabilizing and enriching processes, but these have opposite effects on innovation, under what conditions does each process prevail?" (Penney, Combs, 2013, 1422). Given this theoretical scenario, the purpose of this paper is to explore how and to what extent different levels of family involvement affect business innovation. In order to achieve this goal, limitations shown by the current organizational literature suggest the use of other theoretical approaches. For instance, family science, and social psychology of the family especially, can help to explain family processes and performances (such as innovation propensity), as claimed by previous literature (James et al., 2012, Dyer, Dyer, 2009). To date, this approach has had a limited impact on family business literature (for a review, see Daspit et al., 2017). By applying Olson's circumplex model to the family firms (Olson, 2000; 2011), this research posits that the family's cohesion and flexibility levels play a significant role in the relationship between family involvement and firm innovation propensity. In doing so, this paper highlights a curvilinear relationship between family involvement and firm innovation propensity, as theoretically supposed by previous literature (Penney, Combs, 2013; Sciascia et al., 2013; Daspit et al., 2017).

This paper contributes to the current literature in a threefold way.

Highlighting a curvilinear relationship between family involvement and propensity for innovation, this paper provides an explanation of the limitations shown by previous theoretical 'linear' approaches in explaining this relationship.

Furthermore, highlighting the different ways and intensity of family involvement in the business, this paper addresses family firms' heterogeneity, as advocated by current literature (Melin, Nordqvist, 2007; Sciascia et al., 2013).

Finally, the circumplex model is widely used by counsellors and practitioners in their professional activity. By showing that this approach is also suitable for investigating family firms dynamics academically, this paper builds a bridge between the currently (and too often) separate worlds of scholars and practitioners.

\section{Theoretical background}

Family business literature has frequently highlighted the impact of family' involvement on firm innovation rate (for a literature review see De Massis et al., 2013). Unfortunately, research has until now failed to find a linear correlation between involvement and innovation: several scholars acknowledge this theoretical gap (Padilla-Melendez et al., 2015; Wright \&Kellermans, 2011), in spite of the fact that many theories have attempted to support such a correlation.

For example, 'familiness' (Habbershon et al., 2003), is a variable that can differentiate and characterize the firm, resulting in a competitive 
advantage, as suggested by the resource-based view (RBV) (Habbershon et al., 2003; Sirmon and Hitt, 2003; Habbershon and Williams, 1999; Barney, 1991). Recently, Arzubiaga and colleagues (2019) found that family involvement decreases the positive impact on exploratory innovation, but does not improve the impact on exploitative innovation, unlike expected. Cassia et al (2011) found that shared family values, the desire to defend family reputation and high level of communication among family members are enabling factors for innovation. Conversely, a higher level of risk aversion, less professional management and closeness to the external environment seem to be obstacles in innovation development. However, these authors also affirm that "a number of the proposed factors do not appear to discriminate successful from unsuccessful New Product Development processes" (Cassia et al., 2011, 10). Unfortunately, they are not able to explain these findings, advocating for a better understanding of the family dynamics which underline the innovation processes.

Research based on stewardship theory (Davis, Schoorman, and Donaldson 1997) suggests that family members develop a strong sense of belonging and identification with their own family, and thus they are seldom engaged in opportunistic behaviours. The distinctive stewardship orientation of family versus nonfamily firms may idiosyncratically affect the characteristics of the product innovation process (De Massis et al., 2015). Following this approach, Kellermans and colleagues (2012) introduced the concept of family members reciprocity. In their view (see also Astrachan et al., 2002; Klein et al., 2005), reciprocity, by triggering altruistic dynamics and knowledge sharing among family members (Eddleston, Kellermans, 2007), fosters innovation rate. However, their research does not fully support the hypothesis. Their conclusion is that the influence of family involvement on innovation propensity is a complex phenomenon, which does not follow a linear relation, and could result both in positive and negative outcomes.

Literature suggests that also Agency Theory does not show a good fit for explaining high/low innovation rate. On one hand, this approach suggests that a typical value that is considered to significantly influence the dynamics of family firms is altruism (Dyer, 2003; Shulze et al., 2001). As argued by Shulze et al. (2001), altruism leads family members to be considerate of one another, promote and sustain the family bond; and this in turn promotes loyalty, commitment to the family firm's long-term prosperity and knowledge sharing. On the other hand, in a family firm, the Principal and the Agent are often the same person, and altruism could affect strategic choices about innovation. For instance, hiring a next generation member who is not properly skilled and, as a consequence, undermining knowledge improvement and eventually hindering the innovation rate. Moreover, literature investigating the decentralization of strategic decisions to nonfamily members is still inconclusive: this kind of delegation could have both negative (Zahara, 2015) and positive (Madanoglu et al., 2016) consequences for innovation.

Finally, research based on Behavioural Theory suggests that family firms are strongly focussed on maintaining strategic control among family members. For instance, some authors (Astrachan and Jaskiewicz 2008; Zellweger and Astrachan 2008), highlight the relevance of non-economic goals as development and conservation of socioemotional wealth (SEW) for the family (GomezMejia et al., 2007). Berrone and colleagues affirm that "family firms are typically motivated by, and committed to, the preservation of their SEW, referring to non-financial aspects or "affective endowments" of family owners" (Berrone et al., 2012, p. 259). However, literature suggests that there is also a dark side of involvement that can lead to opportunism, complacency and blind faith (Eddleston \& Kidwell, 2012; Ferrari, forthcoming; Steier, 2001; Sundaramurthy, 2008), and can also negatively affect proactive stakeholder engagement (Kellermans et al., 2012). More recently, Dieguez-Solo et al. (2016), analyse the relationship between family involvement and innovation through the SEW lens. They find that this relationship is not entirely clear, leading to negative results in short-term exploration, but positive in long-term exploitation.

In summary, organizational literature hasn't yet answered the question: in a family firm, in which conditions does family involvement foster (or hinder) firm innovation propensity? This paper suggests that current literature fails to explain the innovation process because it searches for a direct relationship between family involvement and innovation levels. Chrisman et al. (2014b) posit that the difference in outcomes could be due to a complex system of factors like continuity, command, community and 
connections, requiring a non-linear approach in order to explain the outcomes of family involvement. An alternative, psychological approach would therefore suggest that the relationship between family involvement and firm innovation propensity could be curvilinear rather than linear: too high or too low cohesion/ flexibility levels could undermine the propensity to innovation. Thus, drawing on social psychology of the family, this research adopts the circumplex model (Olson, 2011; see Figure 1 below), a curvilinear model of the family involvement.

\section{The Circumplex model}

Social psychology of the family literature shows that family flexibility/adaptability plays a prominent role in ensuring some desired organizational outcomes such as reciprocity, knowledge development and, more in general, balanced relationships between family members (Olson, 2000; Michael-Tsabari, Lavee, 2012).

Every situation experienced by a family can be defined by assessing two different and variable family features: its cohesion (how self-oriented the family is) and its flexibility or adaptability (how changeable and adaptable the relationships within the family are; for an assessment of these dimensions, see also Beavers \& Hampson, 1995; Olson, 2000; 2011; Michael-Tsabari, Lavee, 2012). Family cohesion is defined as "the emotional bonding that family members have towards one another" (Olson, 2000: 145), and family flexibility refers to the "amount of change in [the family's] leadership, role relationships and relationship rules" (Olson, 2000: 147).

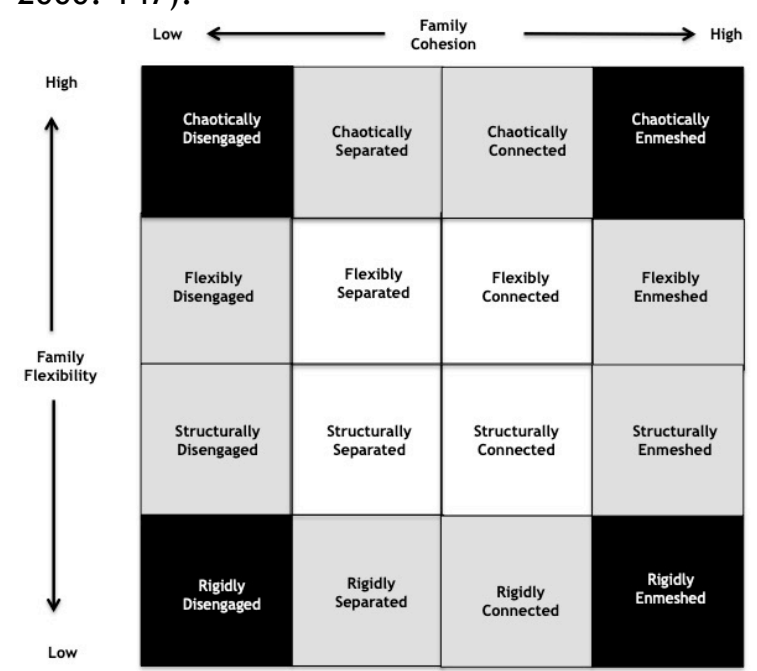

Figure 1 The circumplex model (source: Olson, 2000).

Regarding the different levels of cohesion, a family could be: disengaged, separated, connected, or enmeshed. A very low cohesion level (disengaged family) is characterized by lack of commitment, antagonism among family members, and a general family trend for expulsion and/or escape. Disengaged family systems are composed of highly independent members who have little or no attachment or commitment to the family. Members often "do their own thing" without seeking support or guidance from other family members (Olson, 2000: 147).

A low or moderate cohesion level (separated family) is characterized by strong individualism, competition for the resources, and infrequent communication among members (both qualitative and quantitative). A medium-high or high cohesion level (connected family) is characterized by commitment but at the same time respect for individual needs and career/life paths and full support (both economical and emotional) of members' autonomy. Finally, a very high cohesion level (enmeshed family) is characterized by the collective prevailing over individuals; strict resource sharing; continuous boycotting and undermining of members' autonomy.

Moreover, regarding the different levels of internal relationships, flexibility/adaptability, a family could be: strict/rigid, structured, flexible/versatile, or chaotic. A very low flexibility level (rigid family) is characterized by un-modifiable role/job descriptions, and recursive dynamics (both affective and relational). In a family characterized by low or moderate flexibility level (structured family) the family system, especially the senior, strictly controls the affective and relational features, restricting and norming them. A high flexibility level (flexible family) is characterized by a flowing relational system, and is well suited to different situations. The leadership is circulating, and makes the most of the juniors (for example, their skills or attitudes). A very high flexibility level (chaotic family) is characterized by a lack of reference points, the relational system is neglected, and the seniors do not provide guidance.

Each dimension/variable (both cohesion and flexibility) could be described in a curvilinear graph, whose extreme values are negative (dysfunctional). Due to the aforementioned familiar dimensions/variables, given the different values of both cohesion and flexibility, each combination could result in 16 different kinds of family. Among these 16 types, family businesses experience the highest likelihood of positive outcomes in families which are balanced, that is at the same time both connected/separated and flexible/structured (Michael-Tsabari, Lavee, 2012).

The circumplex model has been previously applied in order to investigate several family features and family firms' performance (for a review, see Daspit et al., 2017). Lee (2006) 
investigated the impact of balanced cohesion and flexibility on job satisfaction; Nosé, Korunka, Frank, \& Danes (2015) found that balanced family structures reduce relationship conflict within the family. Additionally, circumplex research shows that balanced levels of cohesion and flexibility help the family firm to survive through business transmission (Labaki, 2011). More generally, balanced family structures lead to positive outcomes in family performance (Zody, Sprenkle, MacDermid, \& Schrank, 2006) and even ensure success over multiple generations (Michael-Tsabari \& Lavee, 2012). As a conclusion, ongoing literature supports the application of the circumplex model to family business. However, as remarked on by Daspit and colleagues "these studies tend to address the impact of only one or two extreme family structures on family firms [...], thus potentially overlooking family system effects that a more detailed and nuanced application of circumplex theory might uncover" $(2017,13)$.

Regarding firm innovation levels, as a curvilinear model, Olson's circumplex model seems well suited for explaining the impact of family involvement on the firm's innovation propensity: as suggested by previous literature, unbalanced/dysfunctional situations could lead to negative outcomes, also for innovation propensity.

Thus, it is possible to set the following hypothesis:

H1: Family firms in an unbalanced situation (rigid, chaotic, disengaged or enmeshed) show lower levels of innovation propensity compared to firms in balanced situations.

\section{The research}

The survey was carried out on a sample of Italian family SMEs $(\mathrm{N}=125)$. These firms are characterized by a full overlapping between ownership, family, and management; furthermore, in these firms (at least in the smallest ones) the owners are often directly involved in production (Ward, 1987; Gersick et al., 1997; Tagiuri, Davis, 1996). This kind of firm was chosen due to the fact that they are the most widespread type in the Italian context (Bugamelli et al., 2012; Pellegrino and Zingales, 2014; see also the general framework of Curimbaba, 2002).

The sample

In order to select the participants, the research was carried out with the help of a young entrepreneurs association ('Giovani Impenditori Confindustria'). Starting from the association's database, an exploratory mailing list was formed in order to collect the consensus to participate in the research.
Following this, a second more specific mailing was done in order to find the firms with two specific characteristics:

1. A single family must share at least $50 \%$ of the ownership;

2. The strategic decisions must be managed by the family

The data gathering started at the beginning of November, 2017, and was completed by the end of April 2018; 125 questionnaires were collected.

\section{The methodology}

Innovation propensity was measured using the Organisational Innovativeness Questionnaire (Wang, Ahmed, 2004). This tool is a welldeveloped and validated measurement instrument of organisational innovation propensity, based on five factors:

- Product innovativeness, defined as "the novelty and meaningfulness of new products introduced to the market in a timely fashion" (Wang, Ahmed, 2004, 304). Item example: "In new product and service introductions, our company is often first-to-market".

- Market innovativeness, defined as "the newness of approaches that companies adopt to enter and exploit the targeted market" (Wang, Ahmed, 2004, 305). Item example: “In comparison with our competitors, our products' most recent marketing programme is revolutionary in the market".

- Process innovativeness, defined as "an organisation's ability to exploit their resources and capabilities, and most importantly, the ability to recombine and reconfigure its resources and capabilities to meet the requirement of creative production" (Wang, Ahmed, 2004, 305). Item example: "We are constantly improving our business processes".

- Behavioural innovativeness, "demonstrated through individuals, teams and management that enable the formation of an innovative culture, the overall internal receptivity to new ideas and innovation" (Wang, Ahmed, 2004, 305). Item example: "In our company, we support individuals who do things in a different way", and

- $\quad$ Strategic innovativeness, defined as "an organisation's ability to identify external opportunities in a timely fashion and match external opportunities with internal capabilities in order to deliver innovative products and explore new markets or market sectors" (Wang, Ahmed, 2004, 306). Item example: "Key executives of the firm are willing to take risks to seize and explore "chancy" growth opportunities".

Family cohesion and flexibility was measured with the short Italian version of Olson's FACES IV

Ferrari, F. (2019). Does too much love hinder innovation? Family involvement and firms' innovativeness in family-owned Small Medium Enterprises (SMEs). European Journal of Family Business, 9(2), 115-127. 
(Loriedo et al., 2013). This tool provides six different sub-scales for each family dimension:

- Disengaged (item example: "When we are at home, each of us seems to avoid the others");

- Separated/Connected (item example: "Each of us feels involved in the other family members' lives");

- $\quad$ Enmeshed (item example: "We spend too much time together");

- $\quad$ Strict/Rigid (item example: "In family relationships, each of us plays a strictly defined role");

- $\quad$ Structured/Versatile (item example: "Our family explores different work-related problem-solving methods/ ways to solve problems) and

- Chaotic (item example: "In our family we always seem disorganized").

The relationship between family situation and innovation propensity was measured with a correlation test. Moreover, statistically significant relationships were also measured with a regression analysis test.

Empirical evidence (Zahra, 2005; Duran et al., 2016; Zellweger, Sieger, 2012) suggests that when the first generation is still active in the family business, the propensity to innovate is lower. Literature suggests that innovation is often perceived as a threat to the family firm past history (Dyer \& Whetten, 2006), and this fact could even lead to organizational failure (Haveman, Khaire, 2004). However, further evidence suggests that the type of involvement matters more than the involved generation (Arzubiaga et al., 2019). Given this ambiguous empirical evidence, the relationship between the family generation and the innovation propensity was controlled using an ANOVA test.

\section{Findings}

Statistical analysis based on the available 125 returned, correct, and complete questionnaires shows the following results.

These findings support a negative correlation between the overall organizational innovation propensity and both enmeshed families (-.275) and chaotic families (-.402). Enmeshed families show also a stronger negative correlation with Product Innovation (-.435). Chaotic families also show a negative correlation both with Strategic Innovation (-.330) and Process Innovation (-.373). Disengaged families show a significant negative correlation with Strategic Innovation (-.300). Finally, rigid families show no correlation with the overall organizational innovation propensity level. For each statistically significant correlation, a linear regression was calculated to predict innovation level based on specific family situation.

Findings suggest a significant regression equation was found for enmeshed business families in affecting overall Innovation $((\mathrm{F} \mathrm{1}, 124)=19.537$, $\mathrm{p}>.05)$, with an $\mathrm{R}^{2}$ of .0129 ; constant $=3.327$ 0.10 (enmeshment)) and Product Innovation especially $\left((\mathrm{F} \mathrm{1}, 124=29.016, p>.05)\right.$, with $R^{2}$ of 0.1830 ; constant $=3.529-0.187$ (enmeshment)). For each point of enmeshment level measured with the Italian short version of Olson's FACES IV, overall family firm Innovation decreased by 0.10 and Product Innovation level decreased by 0.19 .

Findings also show that a significant regression equation was found for chaotic business families in affecting overall Innovation $((F) 1,124)=$ 23.938, $\mathrm{p}>.05)$, with an $\mathrm{R}^{2}$ of .0 .1550 ; constant $=$

\begin{tabular}{|c|c|c|c|c|c|c|c|c|c|c|c|c|}
\hline & Enmeshed & Chaotic & Disengaged & Rigid & Cohesion & Flexibility & Innovation & Product & Market & Strategic & Process & Behavioural \\
\hline Enmeshed & 1 & & & & & & & & & & & \\
\hline Chaotic & 0,3072 & 1 & & & & & & & & & & \\
\hline Disengaged & 0,1186 & 0,5137 & 1 & & & & & & & & & \\
\hline Rigid & $-0,0053$ & $-0,2114$ & $-0,1508$ & 1 & & & & & & & & \\
\hline Cohesion & $-0,2609$ & $-0,408$ & $-0,4732$ & 0,3227 & 1 & & & & & & & \\
\hline Flexibility & $-0,2728$ & $-0,3722$ & $-0,3153$ & 0,0064 & 0,2776 & 1 & & & & & & \\
\hline Innovation & $-0,2753^{* * *}$ & $-0,4023^{*}$ & $-0,169$ & $-0,1003$ & 0,0268 & 0,1997 & 1 & & & & & \\
\hline Product & $-0,4355^{*}$ & $-0,0759$ & 0,1237 & $-0,1397$ & $-0,2076$ & $-0,1593$ & 0,4691 & 1 & & & & \\
\hline Market & $-0,1735$ & $-0,2214$ & 0,0047 & $-0,1257$ & $-0,0189$ & $-0,0882$ & 0,5644 & 0,1634 & 1 & & & \\
\hline Strategic & $-0,0667$ & $-0,3309^{* * *}$ & $-0,3006^{* * *}$ & 0,0337 & 0,0305 & 0,2435 & 0,4102 & $-0,0045$ & $-0,0286$ & 1 & & \\
\hline Process & $-0,2347$ & $-0,3733^{* * *}$ & $-0,2622$ & 0,0667 & 0,1848 & $0,3261^{* * *}$ & 0,7268 & 0,2224 & 0,0577 & 0,3148 & 1 & \\
\hline Behavioural & 0,1045 & $-0,2011$ & $-0,0731$ & $-0,0852$ & 0,1257 & $0,3017^{* * *}$ & 0,7007 & 0,0179 & 0,3732 & 0,1098 & 0,487 & 1 \\
\hline
\end{tabular}

Ferrari, F. (2019). Does too much love hinder innovation? Family involvement and firms' innovativeness in family-owned Small Medium Enterprises (SMEs). European Journal of Family Business, 9(2), 115-127. 
$3.362-0.135$ (chaotic situation)). Strategic Innovation $\left((\mathrm{F} 1,124=15.249, \mathrm{p}>.05)\right.$, with $\mathrm{R}^{2}$ of 0.1023 ; constant $=3.284-0.183$ (chaotic situation $))$, and Process Innovation $((\mathrm{F} 1,124=$ $20.075, p>.05)$, with $R^{2}$ of 0.1323 ; constant $=$ 3.3845 - 0.213 (chaotic situation)). For each point of chaotic situation level measured with the Italian short version of Olson's FACES IV, family firm Innovation decreased 0.16, Strategic Innovation level decreased by 0.10 and Process Innovation level decreased by 0.21 .

Furthermore, findings show that a significant regression equation was found for disengaged business families in affecting Strategic Innovation $((F 1,124)=12.321, p>.05)$, with an $R^{2}$ of .083; constant $=3.218-0.149$ (disengaged situation). For each point of disengaged situation level measured with the Italian short version of Olson's FACES IV, family firm Strategic Innovation decreased by 0.08 .

In general, family cohesion and flexibility show no significant correlation with the organizational innovation propensity level. However, flexibility shows a positive correlation with Process and Behavioural Innovation (.33 and .30 respectively). Once more, for these statistically significant correlations, a linear regression was calculated to predict innovation level based on flexibility level of the family situation.

Findings show that a significant regression equation was found for flexible business families in affecting Process Innovation $((\mathrm{F}) 1,124=$ $14.753, p>.05)$, with $R^{2}$ of 0.10 ; constant $=2.412$ +0.353 (flexibility)) and Behavioural Innovation $\left((\mathrm{F} 1,124=12.413, \mathrm{p}>.05)\right.$, with $\mathrm{R}^{2}$ of .083 ; constant $=2.246+0.339$ (flexibility)). For each point of flexibility level measured with the Italian short version of Olson's FACES IV, family firm Process Innovation increased by 0.35 and Behavioural Innovation level increased by 0.34 .

Given these results, $\mathrm{H} 1$ (Family firms in an unbalanced (rigid, chaotic, disengaged or enmeshed) situation show lower levels of innovation compared to firms in balanced situations) is supported with the exception of a rigid situation. Moreover, the sample shows no difference in organizational innovation propensity controlling for the current owner generation (see Table 2).

\section{Discussion}

\section{Theoretical contributions}

Due to the limitations previously shown by organizational literature in explaining how family involvement affects the firm's innovation rate, this paper fills a theoretical gap shifting the focus from the organizational to the psychological dimension. However, a circumplex model does not replace previous theoretical approaches, but provides a complementary explanation for the relationship between family involvement and innovation propensity. Resource-Based View and Behavioural Theory in particular are effectively complemented by the circumplex model.

Previous research suggested that the Resource Based View does not show a good fit for explaining negative outcomes (Cassia et al., 2011). Literature (Arzubiaga et al. 2019; Minichilli et al. 2010) suggests that family involvement may have a negative impact on innovation propensity due to the level of heterogeneity of managerial knowledge and skills (see also Cruz, Nordqvist, 2012), but the dynamic behind this impact is not yet clear. This research suggests that only extreme scores on the cohesion dimension of the circumplex model (i.e. enmeshed and chaotic family), are negatively associated with positive outcomes due to a overinvolvement or an insufficient involvement of the family in the firm,. Hence, such unbalanced situations could explain the lack of social capital (e.g. network with stakeholders) and human capital (e.g. skills and knowledge) development, dimensions considered strategic by RBV in innovation propensity. For example, enmeshed and strict/rigid situations could hinder the construction of a network of relationships and strategic partnership (social capital), and boycott the next generations' work experience (e.g. outside the family firm) and their

\begin{tabular}{|c|c|c|c|c|c|c|}
\hline Current & Product & Market & Strategic & Process & Behavioural & \\
\hline generation & Innovation & Innovation & Innovation & Innovation & Innovation & Innovativeness \\
\hline First & 3.4 & 3.1 & 3.3 & 3.5 & 3.6 & 3.4 \\
\hline Second & 3.2 & 2.6 & 2.9 & 3.6 & 3.3 & 3.2 \\
\hline Third or next & 2.9 & 2.7 & 2.8 & 3.6 & 3.1 & 3.1 \\
\hline Sample & 3.2 & 2.8 & 3.0 & 3.6 & 3.3 & 3.2 \\
\hline
\end{tabular}


development of skills and autonomy (human capital).

In addition, this research suggests that the circumplex model helps in explaining the limitations of Behavioural Theory. For instance, striving for control maintenance could undermine the next generation's autonomy and development (Ferrari, 2019; 2017). Recent literature adopting a SEW approach in investigating family firm innovation (see for instance Dieguez-Soto et al., 2016), found a mixed impact (both positive and negative) from family involvement. Moreover, previous literature describes but does not explain heterogeneity in striving for socioemotional wealth (Chrisman \& Patel, 2012), for instance analyzing how socioemotional wealth evolves over generations (Berrone et al., 2012). This study suggests that a limitation in SEW literature could be that it does not consider different levels and types of family involvement. Indeed, cohesion levels which/that are too high, resulting in an enmeshed family, could explain negative effects on the relational system, and consequently generating differences in the extent to which family and non-family firms invest in innovation and the way they manage the innovation process, as suggested by literature (De Massis et al., 2015). In other words, this research suggests that too much or too little attention to socioemotional wealth leads to negative outcomes in family firm innovation propensity.

Beyond the adopted theoretical approach, one major criticism of family business literature is that family firms have been treated as a homogeneous population, as highlighted by some authors (Melin, Nordqvist, 2007; Sciascia et al., 2013). Literature often reflects the underlying heterogeneity of family businesses (e.g., Chrisman, Chua, Pearson, \& Barnett, 2012), heterogeneity that forces researchers to go beyond a simple family versus non-family dichotomy to explain why the overlapping between the family and the business has different effects in different family firms. This paper highlights that, considering the levels of cohesion and flexibility, the heterogeneity of family businesses can result in (up to sixteen) different situations, each potentially different from the others regarding the impact on business performance.

In summary, previous theoretical approaches have offered suitable explanations for innovation propensity in balanced situations (separated, connected, structured, flexible/versatile family and all combinations of these), while the circumplex model shows a better fit in also explaining the (scarce) innovation propensity in unbalanced situations (enmeshed, disengaged, and chaotic). Furthermore, by specifically measuring the levels of involvement and flexibility of entrepreneurial families, the circumplex model seems to be more accurate in addressing firm heterogeneity, as advocated by recent (and current) literature (Madanoglu et al., 2016; Arzubiaga et al., 2019).

\section{Specific empirical contributions}

This paper provides evidence that unbalanced families show the lowest innovation propensity levels: accordingly with Hypothesis 1, balanced levels of family cohesion and flexibility show no significant correlation with the overall organizational innovation propensity level. Furthermore, by identifying specific correlations between factors, it is therefore possible to design targeted interventions in order to improve innovation (see below for practical implications). For instance, flexibility shows a positive correlation with Process and Behavioural Innovation (.33 and .30 respectively). This fact could be explained by considering that innovation in processes and behaviours demands new ways to face organizational routines: hence, flexibility seems to show a good fit in ensuring that organizational outcomes are achieved. The effects of some flexibility-fostering managerial practices, (e.g. job rotation: Ortega, 2001) and other similar human resource innovations (e.g. horizontal rather than vertical internal career), on performance have been documented (Ichniowsky et al. 1996, 1997, 1999).

In contrast, cohesion shows a weak, but negative correlation with Product Innovation (.21). 'Product innovativeness' is most often referred to as 'perceived newness, novelty, originality, or uniqueness of products' (Henard and Szymanski, 2001): all these features are competence-based and derived from an intimate knowledge of materials and their characteristics. Thus, product innovation is also grounded on knowledge sharing and training activities with non-family members and/or consultants, and cohesion could hinder that processes. Therefore, these findings suggests that, even in a balanced family, cohesion undermines 'product innovativeness'.

Disengaged families show a significant negative correlation with Strategic Innovation (-.30), and a weak negative correlation with Process Innovation (-.26). Disengaged family systems consist of family members who are not cohesive and have little or no family loyalty, thus undermining 'behavioural innovativeness' (both at individual and team levels), which in contrast demonstrates management's willingness to change, and commitment to encouraging new ways of doing things, as well as the willingness to foster new ideas (Rainey, 1999). At the same time, 'process innovativeness' is fostered by contributions in terms of ideas, new ways of doing things, desire for both exploitative and explorative dynamics. Individuals who fulfil these 
ambidextrous roles might face tensions in terms of different kinds of cognitive orientation requested by contradictory activities, such as efficiency-oriented versus variability-increasing tasks (Bonesso, Gerli, Scapolan, 2014; Swart \& Kinnie, 2007). Hence, a scarce sense of belonging could easily undermine individual ambidexterity and eventually result in low Process Innovation Enmeshed families show a negative correlation with both the overall innovation propensity level $(-.275)$ and with Product Innovation (-.43). These findings seem to support previous empirical research, although it was carried out on strategic management rather than innovation propensity specifically. For instance, Vozikis et al. (2013) underline the relationship between family cohesion and preference for family in firm-level decisions. Extremely high levels of cohesion in the family translates to preference for family in the family firm, thus hindering the non-family members' contributions in terms of ideas, knowledge and skills, all issues at the base of new product development. Thus, as suggested by Daspit and colleagues $(2017,17)$, "if non-family members are indeed less likely to be hired and promoted, the organization is likely to suffer from a lack of specialized skills and diverse knowledge resources gained from the employment and advancement of non-family members".

In this sample, chaotic families show a negative correlation both with Strategic Innovation (-.32) and Process Innovation (-.37). The correlation matrix (see Table 1) also shows a significant correlation (.31) between Strategic and Process Innovation, suggesting the prominent role played by these intertwined features and their effect on firm performance.

Becker (2004) suggested that the chaotically linked system hinders intra-firm coordination and stability due to the lack of synergistic routines that develop in the chaotic context, thus undermining the development of both process and strategic innovation. Moreover, Becker also suggested (2004) that because the internal environment is inconsistent due to the chaotic family structure, the firm suffers from a lack of order, efficiency, and certainty, which may undermine all aspects of firm performance (Chrisman, Memili, \& Misra, 2013).

In summary, these empirical findings suggest that unbalanced family situations (enmeshed, chaotic, disengaged) lead to negative outcomes in innovation propensity, thus supporting what is being hypothesized by ongoing theoretical literature (see, for instance, Daspit et al., 2017). Hence, the circumplex model provides rich suggestions on the role played by extreme cohesion and flexibility levels on family firm innovation levels/ innovation propensity (levels).

\section{Conclusions}

The circumplex model seems to be suitable for overcoming the limitations demonstrated by other organizational approaches. This paper suggests that an over-involved/flexible and/or insufficiently involved/flexible family in the firm both lead to negative outcomes in innovation propensity. Therefore, FACES IV is a suitable tool for investigating if and in which conditions family relationships are to the detriment of firm performance, in particular to the innovation propensity. In conclusion this research, by providing empirical evidence supporting the circumplex model's application to family firms, has advanced several streams of research suggested by recent theoretical literature (Daspit et al., 2017).

First, this paper integrates current literature, offering insights into how the family system is a source of family firm heterogeneity, identifying why differences in innovation propensity exist rather than simply highlighting the existence of those differences. Indeed, theoretical models such as Resource Based View, Agency Theory, Stewardship Theory and Behavioural Theories show significant limitations in explaining different family firms' performance in innovation propensity. Drawing on Psychology of the Family literature, this research suggests that these limitations are due to the fact that cited approaches posit a linear relationship between family involvement and innovation propensity. Instead, the circumplex curvilinear model shows a better fit for explaining the family involvement impact on innovation propensity.

A further contribution of this paper is to support a theoretical model which is well-suited for defining the different situations in which family involvement leads to negative or positive outcomes in term of innovation level/ innovation propensity. More specifically, this paper provides evidence that some specific conditions play a role in fostering such innovation: enmeshed and mostly chaotic families show lower innovation propensity levels. In doing so, this paper responds to the call for integrating familyspecific insights into family business studies (Jennings, Breitkreuz, \& James, 2014).

Third, previous literature has tended to address the impact of only one or two extreme family structures on family firms (e.g., Michael-Tsabari \& Lavee, 2012; Penney \& Combs, 2013): in contrast, by applying a curvilinear model, this paper addresses its investigation to all family system dimensions, highlighting the specific impact of each dimension on family firm outcomes.

Finally, focusing on organizational innovation propensity, this paper responds to the call for further empirical research which investigates

Ferrari, F. (2019). Does too much love hinder innovation? Family involvement and firms' innovativeness in family-owned Small Medium Enterprises (SMEs). European Journal of Family Business, 9(2), 115-127. 
specific firm outcomes by applying the circumplex model, (Daspit et al., 2017).

Practical implications

As suggested by Daspit and colleagues (2017), the circumplex model offers a guiding framework that can diagnose the extent to which family systems are balanced and how the effects of balanced or unbalanced family dynamics affect the family firm. In addition, focusing on five different 'innovativeness' dimensions (product, market, strategy, behaviour, process), this paper offers a suitable approach in order to identify the specific weaknesses at the base of negative results in one or more of such dimensions. Consequently, this approach also helps psychologists and, more in general, practitioners in designing the proper interventions (e.g. training activities, or organizational re-design etc.) in order to foster organizational innovation propensity. The complex model applied to innovation thus shows real potential in bridging the academic world and the consulting world, as is advocated in this Special Issue (EJFB, forthcoming).

\section{Limitations and suggestions for future research} Beyond contributions and practical implications, this paper also presents several limitations.

Findings from this study could be due to a country bias in the sampling process. In fact, the Italian economy consists of small family-managed firms, with low innovation rate, and low capabilities in human resources management or for improving human and financial capital (Eurostat, 2013). Further research would have to involve samples from different organizational populations.

Moreover, it could be very insightful to investigate the specific innovation propensity level of family firms in extreme unbalanced situations (chaotically disengaged, rigidly enmeshed, etc.): due to its limited dimension (few cases belong to these dysfunctional categories), this sample does not allow for this kind of analysis.

Finally, from a methodological point of view, this research gathered data using the short Italian version of the Olson's FACES questionnaire (Loriedo et al., 2013): hence, these findings should be validated in future research by also collecting data with the original full-lengthversion of the Olson questionnaire.

\section{References}

Arzubiaga, U., Maseda, A., \& Iturralde, T. (2017). Exploratory and exploitative innovation in family businesses: The moderating role of the family firm image and family involvement in top management. Review of Managerial Science, 47(7), 1343.

Astrachan, J. H., and P. Jaskiewicz (2008). Emotional Returns and Emotional Costs in Privately
Held Family Businesses: Advancing Traditional Business Valuation. Family Business Review 21(2), 139-149.

Astrachan, J. H., Klein, S. B., \& Smyrnios, K. X. (2002). The F-Pec scale of family influence: A proposal for solving the family business definition problem. Family Business Review, 15(1), 45-58.

Barney J.B. (1991). Firm resources and sustained competitive advantage. Journal of Management, 171, 1, 99-120.

Beavers W.R., Hampson R.B., (1995). Misurare la competenza famigliare: il modello sistemico di Beavers, tr. it. in Ciclo vitale e dinamiche familiari, a cura di F. Walsh, Franco Angeli, Milano.

Becker, M. C. (2004). Organizational routines: A review of the literature. Industrial and Corporate Change, 13(4), 643-677.

Berrone, P., Cruz, C., \& Gomez-Mejia, L. R. (2012). Socioemotional Wealth in Family Firms: Theoretical Dimensions, Assessment Approaches, and Agenda for Future Research. Family Business Review , 25(3), 258-279.

Berrone, P., Cruz, C.C., Gomez-Mejia, L.R., \& Larraza Kintana, M. (2010). Socioemotional wealth and corporate response to institutional pressures: Do family-controlled firms pollute less? Administrative Science Quarterly, 55(1), 82-113.

Block, J. H. (2012). R\&D investments in family and founder firms: An agency perspective. Journal of Business Venturing. 27, 248-265.

Bonesso S., Gerli F., \& Scapolan A.. (2014). The individual side of ambidexterity: Do individuals' perceptions match actual behaviors in reconciling the exploration and exploitation trade-off? European Management Journal, 32 392-405

Bugamelli M., Cannari L., Lotti F. \& Magri S., (2012). Il gap innovativo del sistema produttivo italiano: radici e possibili rimedi, in A. Arrighetti A. Ninni (a cura di) La trasformazione 'silenziosa' Cambiamento strutturale e strategie d'impresa nell'industria italiana, Università di Parma, Collana di Economia Industriale e Applicata, http://dspace-

unipr.cineca.it/bitstream/1889/2565/1/La_trasfor mazione_silenziosa-A\%20Arrighetti_A\%20Ninni.pdf

Cadieux L., Lorrain J., \& Hugron P. (2002). Succession in Women-Owned Family Businesses: A Case Study, Family Business Review, 15, 17.

Carnes, C.M. \& Ireland, R.D. (2013). Familiness and innovation: Resource bundling as the missing link. Entrepreneurship Theory and Practice, 37(6), 13991419.

Carney M. (2005). Corporate Governance and Competitive Advantage in Family-Controlled Firms. Entrepreneurship Theory and Practice 29(3), 249265.

Cartwright, \& D. Zander, A. (1953). Group Dynamics: Research and Theory. Row, Peterson, Evanston.

Cartwright, D., \& Zander, A. (1968). Origins of group dynamics. In D. Cartwright \& A. Zander (Eds.), Group dynamics: Theory and research (3rd ed., pp. 3-21). New York: Harper \& Row.

Chen, H.-L., \& Hsu, W.-T. (2009). Family ownership, board independence, and R\&D investment. Family Business Review, 22, 347-362.

Chrisman, J .J., Fang, H., Kotlar, J., \& De Massis, A. (2014b). A note on family influence and the adoption of discontinuous technologies in family 
firms. Journal of Product Innovation Management,32(3), 384-388.

Chrisman, J. J., \& Patel, P. (2012). Variations in R\&D investments of family and non-family firms: Behavioral agency and myopic loss aversion perspectives. Academy of Management Journal, 55, 976-997.

Chrisman, J. J., Chua, J. H., De Massis, A., Frattini, F., \& Wright, M. (2014a). The ability and willingness paradox in family firm innovation. Journal of Product Innovation Management, 32(3), 310-318.

Chrisman, J. J., Memili, E., \& Misra, K. (2013). Nonfamily managers, family firms, and the winner's curse: The influence of noneconomic goals and bounded rationality. Entrepreneurship Theory \& Practice, 38(5), 1103-1127.

Chrisman, J., Chua, J., Pearson, A., \& Barnett, T. (2012). Family involvement, family influence, and familycentered noneconomic goals in small firms. Entrepreneurship Theory and Practice, 36, 267293.

Chrisman, J.J., Chua, J.H., Litz, R. (2004). Comparing the agency costs of family and nonfamily firms: Conceptual issues and exploratory evidence. Entrepreneurship Theory and Practice, 28, 335-354.

Craig, J. B. L., and K. Moores (2006). A 10 Year Longitudinal Investigation of Strategy, Systems, and Environment on innovation in Family Firms. Family Business Review, 19(1), 1-10.

Cruz C., Nordqvist M. (2012). Entrepreneurial orientation in family firms: a generational perspective. Small Business Economy 38(1), 33-49.

Curimbaba, F. (2002). The dynamics of women's roles as family business managers. Family Business Review, 15(3), 239-252.

Daspit, J.J, Madison K., Barnett T., \& Long R.G. (2017), The emergence of bifurcation bias from unbalanced families: Examining HR practices in the family firm using Circumplex Theory, in Human Resource Management Review, Special Issue on "The Role of Family Science Theories for Human Resource Management in Family Firms". http://dx.doi.org/10.1016/j.hrmr.2017.05.003

Davis, J. H., F. D. Schoorman, and L. Donaldson (1997). Toward a Stewardship Theory of Management. Academy of Management Review, 22(1), 20-47.

Davis, P. S., Harveston, P. D. (1998). The influence of family on the family business succession process: A multi-generational perspective. Entrepreneurship Theory and Practice, 22(3), 3153.

De Massis A., Frattini F., Pizzurno E., \& Cassia L. (2015). Product Innovation in Family versus NonfamilyFirms: An Exploratory Analysis. Journal of Small Business Management, 53(1), 1-36.

De Massis, A. (2012), Family Involvement and Procedural Justice Climate Among Nonfamily Managers: The Effects of Affect, Social Identities, Trust, and Risk of Non-Reciprocity. Entrepreneurship Theory and Practice, 36, 6, 1227 1234.

De Massis, A., Frattini, F., \& Lichtenthaler, U. (2013). Research on technological innovation in family firms: Present debates and future directions. Family Business Review, 26(1), 10-31.

Diéguez-Soto, J., Manzaneque, M., \& Rojo-Ramírez, A. A. (2016). Technological Innovation Inputs, Outputs, and Performance: The Moderating Role of Family Involvement in Management. Family Business Review, 29(3), 327-346.

Duran, P., Kammerlander N., Van Essen M., \& Zellweger T. (2016). Doing more with less: Innovation input and output in family firms. Academy of Management Journal, 59, 4, 1224-1264

Dyer, Jr. W.G. (2003). The family: The missing variable in organizational research. Entrepreneurship Theory \& Practice, 27, 4, 401416.

Dyer, W. \& Dyer, W. (2009). Putting the family into family business research. Family Business Review, 22, 216-219.

Dyer, W. G. (1986). Cultural change in family firms. San Francisco and London: Jossy-Bass.

Eddleston, K. A., \& Kidwell, R. E. (2012). Parentchild relationships: Planting the seeds of deviant behavior in the family firm. Entrepreneurship Theory and Practice, 36(2), 369-386.

Eddleston, K., \& Kellermanns, F. W. (2007). Destructive and productive family relationships: $A$ stewardship theory perspective. Journal of Business Venturing, 22(4), 545- 565.

EJFB, Call for Paper for the special Issue "Innovation in family firms: bridging the theoryᄀpractice gap".

Ferrari, F. (2017). The tragedy of having a daughter: construction and reproduction of gender stereotype in Italian family SMEs. Reti, Saperi, Linguaggi. Italian Journal of Cognitive Sciences, 1/2017, 133-152.

Ferrari, F. (2019). In the mother's shadow: exploring power dynamics in family business succession. Gender in Management: An International Journal, 34, 2, 121-139.

Ferrari, F. (forthcoming). Exploring the side effects of socioemotional wealth. A multilevel analysis approach to the dysfunctional dynamics in family business succession. International Journal of Entrepreneurship and Small Business.

Gagné, M., \& E. L. Deci (2005). Self- Determination Theory and Work Motivation. Journal of Organizational Behavior, 26(4), 331-362.

Gersick, K. E. (1997). Generation to generation: life cycles of the family business. Boston, A: Harvard Business Press.

Gomez-Mejia, L. R., K. T. Haynes, M. Nunez-Nickel, K. J. L. Jacobson, \& J. Moyano-Fuentes (2007). Socioemotional Wealth and Business Risks in Family- Controlled Firms: Evidence from Spanish Olive Oil Mills. Administrative Science Quarterly, 52(1), 106-137.

Gudmundson, D., Tower, C. B., \& Hartman, E. A. (2003). Innovation in small businesses: Culture and ownership structure do matter. Journal of Developmental Entrepreneurship, 8, 1-17.

Habbershon T. G. \& Williams M. L. (1999). A resource-based framework for assessing the strategic advantages of family firms. Family Business Review, 12, 1, 1-25.

Habbershon T.G., Williams M. \& MacMillan I.C. (2003). A unified systems perspective of family

Ferrari, F. (2019). Does too much love hinder innovation? Family involvement and firms' innovativeness in family-owned Small Medium Enterprises (SMEs). European Journal of Family Business, 9(2), 115-127. 
firm performance. Journal of Business Venturing, 18, 4, 451-465.

Harvey M., \& Evans R. (1995). Life After Succession in the Family Business: Is It Really the End of Problems? Family Business Review, 8, 3, 2-16.

Haveman H.A., \& Khaire M.V. (2004). Survival Beyond Succession? The Contingent Impact of Founder Succession on Organizational Failure. Journal of Business Venturing, 19, 437-63.

Henard, D.H. \& Szymanski, D.M. (2001). Why some new products are more successful than others. Journal of Marketing Research, 38, 3, 362-75.

Ichniowski, C., \& Prennushi. G. (1997). The effect of human resource management practices on productivity. American Economical Revue, 87(3) 291-313. ,

Ichniowski, C., \& Shaw. K. (1999). The effects of human resource management systems on economic performance: An international comparison of U.S. and Japanese plants. Management Science, 45(5) 704-721.

Ichniowski, C., Kochan T., Levine D., Olson C., \& G. Strauss. (1996). What works at work: Overview and assessment. Industrial Relations, 35(3) 299333.

James, A., Jennings, J., \& Breitkreuz, R. (2012). Worlds apart? Rebridging the distance between family science and family business research. Family Business Review, 25, 87-108.

Jennings, J. E., Breitkreuz, R. S., \& James, A. E. (2014). Theories from family science: A review and roadmap for family business research. In L. Melin, M. Nordqvist, \& P. Sharma (Eds.), SAGE Handbook of Family Business. London: Sage.

Kellermanns, F., Eddleston, K., Sarathy, R., \& Murphy, F. (2012). Innovativeness in family firms: a family influence perspective. Small Business Economics, 38(1), 85-101.

Kets de Vries, M. F. R. (1996). The dynamics of family controlled firms: The good and the bad news. In C. E. Aronoff, J. H. Astrachan \& J. L. Ward (Eds), Family business sourcebook, vol 1 (pp. 312-323). Marietta, GA: Business Owner Resources.

Kim, H., Kim, H., \& Lee, P. M. (2008). Ownership structure and the relationship between financial slack and R\&D investments: Evidence from Korean firms. Organization Science, 19, 404418.

Klein, S. B., Astrachan, J. H., \& Smyrnios, K. X. (2005). The F-PEC scale of family influence: Construct validation, and further implication for theory. Entrepreneurship Theory and Practice, 29(3), 321-339.

Kraatz, M., \& Block, E. (2008). Organizational implications of institutional pluralism. In R. Greenwood, C. Oliver, R. Suddaby,K.SahlinAndersson (Ed.), Handbook of organizational institutionalism: 243-275. London: Sage Publication.

Labaki, R. (2011). The Nova Group case study: Family dynamics in a multigenerational French family business. International Journal of Management Cases, 13(1), 27-42.

Lansberg, I. (1999). Succeeding generations: Realizing the dream of families in business. Boston, MA: Harvard Business School Press.

Lee, J. (2006). Impact of family relationships on attitudes of the second generation in family business. Family Business Review, 19(3), 175-191.
Llach, J., \& Nordqvist, M. (2010). Innovation in family and non-family businesses: A resource perspective. International Journal of Entrepreneurial Venturing, 2: 381-399.

Madanoglu, M., Altinay, L., \& Wang, X. (2016). Disentangling the effect of family involvement on innovativeness and risk taking: The role of decentralization. Journal of Business Research, 69, 1796-1800.

Meyer, J. P., \& Herscovitch, L. (2001). Commitment in the workplace: Toward a general model. Human Resource Management Review, 11(3), 299-326.

Michael-Tsabari N., Lavee Y. (2012). Too Close And Too Rigid: Applying The Circumplex Model Of Family Systems To First-Generation Family Firms. Journal Of Marital And Family Therapy, 38, 1, 105116.

Minichilli A., Corbetta G., MacMillan I.C. (2010). Top management teams in family-controlled companies: 'Familiness', 'faultlines', and their impact on financial performance. Journal of Management Studies, 47(2), 205-222.

Morrison, E. W. (1994). Role definitions and organizational citizenship behavior: The importance of the employee's perspective. Academy of Management Journal, 37(6), 15431567.

Nosé, L., Korunka, C., Frank, H., \& Danes, S. M. (2015). Decreasing the effects of relationship conflict on family businesses. The moderating role of family climate. Journal of Family Issues, doi: $10.1177 / 0192513 \times 15573869$.

Ortega, J (2001). Job Rotation as a Learning Mechanism. Management Science, 47, 10, 13611370.

Padilla-Meléndez A., Dieguez-Soto J., GarridoMoreno. A., (2015). Empirical research on Innovation in Family Business: literature review and proposal of an integrative framework. Revue of business. Management, 17, 56, 1064-1089.

Pellegrino B., Zingales L. (2014), Diagnosing the Italian Disease, Chicago Booth Working Paper. http: / / faculty.chicagobooth.edu/luigi.zingales/pa pers/research/Diagnosing.pdf

Penney, C.R. \& Combs, J.G. (2013). Insights from Family Science: The Case of Innovation. Entrepreneurship Theory and Practice, 37, 6, 14211427.

Ryan, R. M., \& Deci E. L. (2000). Self- Determination Theory and the Facilitation of Intrinsic Motivation, Social Development, and Well-Being. American Psychologist, 55(1), 68-78.

Salvato, C., Minichilli, A., \& Piccarreta, R. (2012). Faster route to the CEO suite: Nepotism or managerial proficiency? Family Business Review, 25(2), 206-224.

Scabini E., lafrate R., (2003), Psicologia dei legami familiari, Carocci, Roma.

Schulze W.S., Lubatkin M.H., Dino R.N. \& Buchholtz A.K. (2001). Agency relationships in family firms: Theory and evidence. Organization Science, 12, 2, 99-116.

Schulze, W.S., Lubatkin, M.H., \& Dino, R.N. (2003). Toward a theory of agency and altruism in family firms. Journal of Business Venturing, 18, 473-490.

Sciascia, S., Clinton, E., Nason, R.S, James, A.E \& Rivera-Algarin, J.O (2013). Family Communication and Innovativeness in Family Firms. Family Relations, 62, 3, 429- 442. 
Sharma P. \& Manikutty, S. (2005). Strategic Divestments in Family Firms: Role of Family Structure and Community Culture. Entrepreneurship: Theory \& Practice, 29, 3, 293311.

Sharma, P., \& Irving, P. G. (2005). Four bases of family business successor commitment: Antecedents and consequences. Entrepreneurship Theory \& Practice, 29(1), 13-33.

Sharma, P., Chrisman, J. J., \& Chua, J. H. (2003a). Predictors of satisfaction with the succession process in family firms. Journal of Business Venturing, 18(5), 667-687.

Sharma, P., Chrisman, J. J., \& Chua, J. H. (2003b). Succession planning as planned behavior: Some empirical results. Family Business Review, 16(1), 115.

Sharma, P., Chrisman, J. J., Pablo, A., \& Chua, J. H. (2001). Determinants of initial satisfaction with the succession process in family firms: A conceptual model. Entrepreneurship Theory and Practice, 25(3), 1-19.

Shepherd, D.A. \& Haynie, M.A. (2009). Family business, identity conflict, and an expedited entrepreneurial process: A process of resolving identity conflict. Entrepreneurship Theory and Practice, 33(6), 1245-1264.

Sirmon D.G. \& Hitt M.A. (2003). Managing resources: Linking unique resources, management, and wealth creation in family firms. Entrepreneurship Theory and Practice, 27, 4, 339-358.

Steier, L. (2001). Family firms, plural forms of governance, and the evolving role of trust. Family Business Review, 14, 353-367.

Stryker S. (1968). Identity Salience and Role Performance. Journal of Marriage and the Family, 4, 558-64.

Sundaramurthy, C. (2008). Sustaining trust within family businesses. Family Business Review, 21, 89102.

Swart, J., \& Kinnie, N. (2007). Simultaneity of learning orientations in a marketing agency. Management Learning, 38(3), 337-357.

Tagiuri, R., \& Davis, J. A. (1996). Bivalent attributes of the family firm. Family Business Review, 9(2), 199-208.

Tajfel H., Turner J.C, (1986) The social identity theory of intergroup behaviour, in S. Worchel, W.G. Austin (Eds.), Psychology of intergroup relations, pp. 7-24, Nelson-Hall Publishers, Chicago

Tidd, J., J. Bessant, and K. Pavitt (2001). Managing Innovation: Integrating Technological, Market and Organizational Change. Chichester, UK: John Wiley \& Sons.

Trott, P. (2008). Innovation Management and New Product Development. Harlow, UK: Financial Times/Prentice Hall.

Uhlaner L.M., (2006), Business Family as Team: Underlying Force for Sustained Competitive Advantage, in Poutziouris P. (edited by), Handbook of Family Business Research , Edward Elgar Publishing.

Vera C. F. \& Dean, M. A. (2005). An Examination of the Challenges Daughters Face in Family Business Succession. Family Business Review, 18, 321-345.

Vozikis, G. S., Weaver, K. M., \& Liguori, E. W. (2013). Do family cohesion and family member skill evaluation affect family business internal or external hiring decisions? Journal of Management Policy and Practice, 14(1), 75-89.

Wagner, J., \& Hollenbeck, J. (1995). Management of organizational behavior (2nd ed.). Englewood Cliffs, NJ: Prentice-Hall.

Ward J. L. (1987). Keeping the family business healthy: How to plan for continuing growth, profitability, and family leadership. Jossey-Brass, San Francisco.

Wright, M., \& Kellermanns, F. W. (2011). Family firms: A research agenda and publication guide. Journal of Family Business Strategy, 2(4), 187-198.

Zellweger T. M. \& Astrachan, J. H. (2008). On the emotional value of owning a firm. Family Business Review, 21 (4), 347-363.

Zellweger T., \& Sieger, P. (2012). Entrepreneurial orientation in long-lived firms. Small Business Economics, 8(1), 67-84.

Zody, Z., Sprenkle, D., MacDermid, S., \& Schrank, H. (2006). Boundaries and the functioning of family and business systems. Journal of Family and Economic Issues, 27(2), 185-206. 